\title{
Implications of Pulp and Paper Mill Primary Sludge Incineration versus Use in Composites Production: Decision-Making Based on Life Cycle Assessment
}

\author{
K. Mustonen ${ }^{1}$, I. Deviatkin ${ }^{2}$, M. Horttanainen ${ }^{2}$, and T. Kärki ${ }^{1}$ \\ ${ }^{1}$ Fibre Composite Laboratory, Lappeenranta-Lahti University of Technology LUT, Lappeenranta 53850, Finland \\ ${ }^{2}$ Department of Sustainability Science, Lappeenranta-Lahti University of Technology LUT, Lappeenranta 53850, Finland
}

Received 13 June 2020; revised 14 August 2020; accepted 18 August 2020; published online 31 December 2020

\begin{abstract}
This paper assesses the environmental consequences of diverting primary sludge from its conventional end-of-life option - incineration - to its use in the production of composites. The study focuses on the environmental consequences of possible decisionmaking rather than simply accounting for the environmental impacts. The study identified that, despite primary sludge incineration has a small climate change impact of $0.01 \mathrm{~kg} \mathrm{CO}_{2}$-eq. per functional unit of $0.44 \mathrm{~kg}$ of primary sludge, primary sludge utilization in the production of composites is a more environmentally friendly option. This is due to a high reduction potential of climate chan ge and abiotic resources consumption through the substitution of virgin plastic of $2.5 \mathrm{~kg} \mathrm{CO}_{2}$-eq. even if the composite production has a higher impact of $1.3 \mathrm{~kg} \mathrm{CO}_{2}$-eq. compared to incineration of the sludge. However, sensitivity analysis showed that the production of composites replacing plastics is only a better alternative for as long as virgin plastic is substituted at the minimum ratio of 1:0.7. The low substitution rate is possible if the properties of the produced composites or their functionality is worse than those of virgin plastic. In such cases, incineration of primary sludge is a better alternative.
\end{abstract}

Keywords: carbon footprint, consequential analysis, decision-making, life cycle assessment, polymer composites, primary sludge, pulp and paper industry, sludge-polymer composites

\section{Introduction}

Pulp and paper industry is at the forefront of the economic development of forest-rich countries, including Canada and Finland. The industry has provided jobs and economic growth over decades, while providing basic products such as pulp and paper and advancing their technologies to production of advanced materials, such as second-generation biofuels and nanocellulose (Bajpai, 2013). However, the industry has been facing serious threats from the fast-expanding digitalization and dematerialization (Hilbert and López, 2011).

To be competitive across and within the industry, pulp and paper companies seek to explore various opportunities to enable the key principles of sustainability including the reduction of the environmental impact and implementation of the circular economy paradigms. One example is the management of wastewater treatment plant (WWTP) residues such as primary and secondary sludge (Faubert et al., 2016). Many such streams found their destiny in multi-fuel boilers thus significantly decreasing the amount of waste landfilled. Still, possibilities for material recovery prior to incineration are prioritized going along with the waste hierarchy.

${ }^{*}$ Corresponding author. Tel.: +358401678550 .

E-mail address: kati.mustonen@lut.fi (K. Mustonen).

ISSN: 2663-6859 print/2663-6867 online

(C) 2020 ISEIS All rights reserved. doi:10.3808/jeil.202000046.
Primary sludge was proven to be a suitable raw material in the production of high-density polyethylene (HDPE)-based composites (Mustonen et al., 2019). The water adsorption and thickness swelling were significantly improved compared to the reference specimen made of wood flour. Furthermore, the impact strength after cyclic freeze-thaw tests showed to be stable.

As to the best knowledge of the authors, there have not been any publications on the assessment of the environmental impact of composites made of primary sludge. At the same time, life cycle assessment (LCA) studies on sewage sludge are plentiful (Suh and Rousseaux, 2002; Lundin et al., 2004; Houillon and Jolliet, 2005; Hong et al., 2009), as well as LCA studies on polymer composites made of waste (Väntsi and Kärki, 2015; Sommerhuber et al., 2017; Liikanen et al., 2019; Fuchigami et al., 2020). Doustmohammadi and Babazadeh (2019) explored the possibilities for designing closed loop supply chain of composite industry which could reduce costs, as well as environmental impacts.

The goal of this paper is to assess the environmental impacts of using primary sludge in the production of polymer composites. The technical feasibility of composites production was studied extensively in previous studies by the authors (Lahtela et al., 2017; Mustonen et al., 2019). Furthermore, the paper compares this alternative utilization scenario with the baseline scenario of primary sludge incineration so as to facilitate decision-making in companies aiming at the reduction of 
their environmental impacts and promotion of the circular economy. Despite a wide range of systems analysis methods available and models built to predict the result based on scientific facts (e.g. the study by Liu et al. (2012)), LCA was used in this study owing to its holistic assessment nature tailored for decision-making.

\section{Methods}

The production of composites using primary sludge was modelled after Mustonen et al. (2019) in terms of the recipe and after the study by Liikanen et al. (2019) in terms of the inventory data. The environmental impacts were assessed using LCA methodology following the ISO standards (SFS-EN ISO 14040, 2006; SFS-EN ISO 14044, 2006). The LCA followed the so-called consequential approach which is often used to help decision-makers on defining the least environmentally burdening option. To a broader extent, the study also includes sensitivity analysis as to show how the data use in LCA can help in uncertain situations.

\subsection{Primary Sludge}

The primary sludge studied in this paper originates from a wastewater treatment plant of a biorefinery located in Lappeenranta, Finland. The solids content of sludge is $43 \%$. The lower heating value of the sludge ranges from $15 \pm 4 \mathrm{MJ} / \mathrm{kg}$ on dry basis (Ojanen, 2001). The sludge mostly consists of wood fibers. Currently, primary sludge is incinerated in a multi-fuel boiler with energy recovery. As the name suggests, the multifuel boiler incinerates various fuels, including bark, wood residues, peat, primary sludge, and secondary sludge, among other fuels.

\subsection{Goal and Scope}

The goal of this study is to compare two scenarios (baseline and alternative scenarios) of primary sludge management, thus facilitating environmentally-oriented decision-making at a company level. The baseline scenario (S0-INC) implies currently practiced incineration of primary sludge in a multifuel boiler. The alternative scenario (S1-COM) studies the use of the primary sludge in the production of composites. The function of the studied product system is to treat primary sludge. The functional unit is set to $0.44 \mathrm{~kg}$ of primary sludge with the properties described in Section 2.1. The functional unit was derived from the alternative scenario where this amount of primary sludge is required to produce $1 \mathrm{~kg}$ of composites.

\subsection{System Boundaries}

The system boundaries of the two scenarios are illustrated in Figure 1. Both scenarios begin with the primary sludge input to the system. Possible impacts associated with the sludge generation was excluded following the zero-burden approach (Ekvall et al., 2007). However, this assumption is increasingly challenged in the upcoming era of circular economy where all waste should be designed for reuse and recycling (Ilic et al., 2018). Sludge thickening and dewatering were also excluded from the system boundaries because of having the same impact on the two scenarios compared.

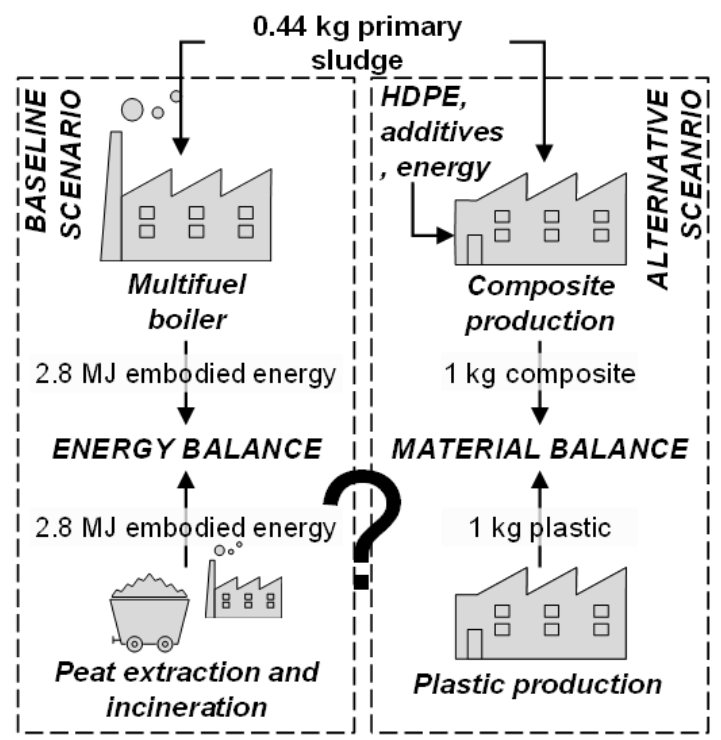

Figure 1. System boundaries of the current situation, i.e. baseline scenario, and of the proposed sludge utilization method, i.e. alternative scenario.

\subsection{Scenarios Studied}

The baseline scenario, S0-INC, includes the impact from incineration of primary sludge. Sludge incineration was modelled using the unit process for wood incineration. A unit process is the smallest element used in life cycle inventory for which input and output data are quantified (SFS-EN ISO 140$40,2006)$. When primary sludge is incinerated, it provides energy for sustaining the combustion of secondary sludge. Therefore, when primary sludge is diverted from incineration, supplementary fuel is to be supplied. In this study, it was modelled that extraction and incineration of peat with the same energy content as in the sludge is avoided through the system expansion approach with a substitution ratio of 1:1 on an embodied energy basis. The exact values and the unit processes used are presented in Section 2.6.

The alternative scenario, S1-COM, includes the impact from the production of composites. The impact includes the production of HDPE, maleic anhydride-grafted polyethylene (MAPE), lubricants, and electricity. The production process is described in Section 2.5. When composites are produced, they can replace materials on the market with equivalent properties. In this study, the substituted material was HDPE plastic. The substitution ratio was 1:1 on a mass basis. The assumption was studied in the sensitivity analysis. The exact values and the unit processes used are presented in Section 2.6.

\subsection{Composites Production}

The production of composites was modelled following the recipe exposed in the study by Mustonen et al. (2019). More specifically, the composites comprised of HDPE $-50 \%$, dewa- 
tered primary sludge $-44 \%$, maleic anhydride-grafted polyethylene (MAPE) $-3.0 \%$, and lubricant $-3.0 \%$. No waste is generated during the production of composites owning to the fact that the process is suitable for waste materials as such.

The inventory data in the production process of composites was modelled after the study by Liikanen et al. (2019). Namely, raw materials were first mixed in the agglomeration process. No prior grinding or size reduction was required for any of the raw materials. Then, the materials were extruded in a conical counter-rotating twin-screw extrusion machine. Finally, the extruded material was cut into decks of specific length. The production process, as well as the raw materials and energy demand are shown in Figure 2.

\section{PRODUCTION OF COMPOSITES}

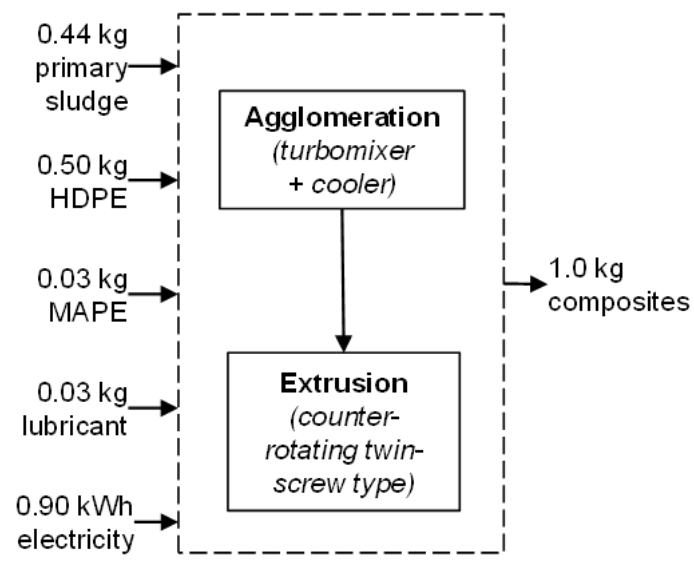

Figure 2. Mass balance and production process of sludgepolymer composites.

\subsection{Life Cycle Inventory}

\subsubsection{Baseline Scenario}

The process of primary sludge incineration was modelled using the process "EU-28: Wood (natural) in municipal waste incineration plant ts <p-agg>" (Sphera, 2017a) with the reference flow of $0.19 \mathrm{~kg}$ which represents the dry mass of primary sludge. Primary sludge supplies $2.8 \mathrm{MJ}$ of energy to the process which was calculated on the mass of dry sludge of $0.19 \mathrm{~kg}$ and its heating value of $15 \mathrm{MJ} / \mathrm{kg}$ on dry basis. To model avoided peat excavation and incineration, the process "FI: Electricity from peat ts" (Sphera, 2014a) was used with the reference value of $1.2 \mathrm{MJ}$ of electricity which represents incineration of peat with the energy content of $2.8 \mathrm{MJ}$.

\subsubsection{Alternative Scenario}

The processes used for the production of $1 \mathrm{~kg}$ of composite and their amounts were: "RER: Polyethylene high density granulate (PE-HD) ELCD/PlasticsEurope <p-agg>” (Sphera, 1999) $-0.5 \mathrm{~kg}$, "EU-28: Lubricants at refinery ts" (Sphera, 2014b) $-0.03 \mathrm{~kg}$, MAPE $-0.03 \mathrm{~kg}$ and modelled after Liikanen et al. (2019), and "FI: Electricity grid mix ts" (Sphera, 2014c) -0.9 $\mathrm{kWh}$. Substituted plastic was "RER: Polyethylene high density granulate (PE-HD) ELCD/PlasticsEurope <p-agg>" (Sphera, 1999) $-1.0 \mathrm{~kg}$. Its extrusion was modelled using the process "GLO: Plastic extrusion profile (unspecific) ts $<\mathrm{u}$-so $>$ " (Sphera, $2017 \mathrm{~b}$ ) and supplying required intermediate flows in the process, such as compressed air, thermal energy from natural gas, electricity, and lubricants.

\subsection{Life Cycle Impact Assessment}

The environmental impact was modelled using the product environmental footprint method implemented in software "GaBi ts" as "EF2.0 (Environmental Footprint 2.0)" (Sphera, 2020). The method covers 16 areas of environmental concern and also distinguishes between biogenic, fossil, land-use change induced impacts on climate change. For simplicity, only the impacts on climate change and consumption of abiotic energy carriers were reported in the study.

\section{Results}

The results of the LCA study showed lower impact on climate change achieved in the alternative scenario S1-COM (Figure 3 and Figure 4). In scenario S1-COM, the direct emissions from composites production were $1.3 \mathrm{~kg} \mathrm{CO}_{2}$-eq., while the avoided impact from plastic substitution was $-2.5 \mathrm{~kg} \mathrm{CO}_{2}-$ eq., thus cumulatively resulting in the avoided impact of -1.2 $\mathrm{kg} \mathrm{CO}$-eq. Despite the direct emissions from incineration of primary sludge in the baseline scenario S0-INC of $0.01 \mathrm{~kg} \mathrm{CO}_{2-}$ eq. were significantly lower than from the production of composites, the avoided impact from peat substitution of $-0.4 \mathrm{~kg}$ $\mathrm{CO}_{2}$-eq. was significantly lower than the avoided impact from plastic substitution. An identical situation is seen in the consumption of fossil energy carriers.

\section{Discussion}

\subsection{Substituted Supplementary Fuel}

Peat was chosen as a supplementary fuel to be combusted if sewage sludge were used in the composites production. However, other fuels could also be used. Since we look into the embodied energy, not much difference is expected between the fossil fuels, such as peat, coal, or natural gas. This is because less fuel would be needed to provide the same energy with higher energy content. However, if biobased fuels such has biomass are used as supplementary fuels, then the avoided impact on the baseline scenario approaches zero meaning almost no avoided impact.

\subsection{Plastic Substitution Rate}

In the default situation, a 1:1 plastic substitution rate on a mass basis was considered. However lower substitution rates could happen due to better physical properties of products made of virgin plastic. It would mean in turn that less plastic would be used. To reflect it, a breakthrough curve was created to find the minimum substitution ratio of plastic (Figure 5). The results indicated that per $1.0 \mathrm{~kg}$ of composite material produced, at least $0.7 \mathrm{~kg}$ of plastic made of virgin polymers should be dis- 
placed on the market. Otherwise, the baseline scenario starts to become a better sludge management option.

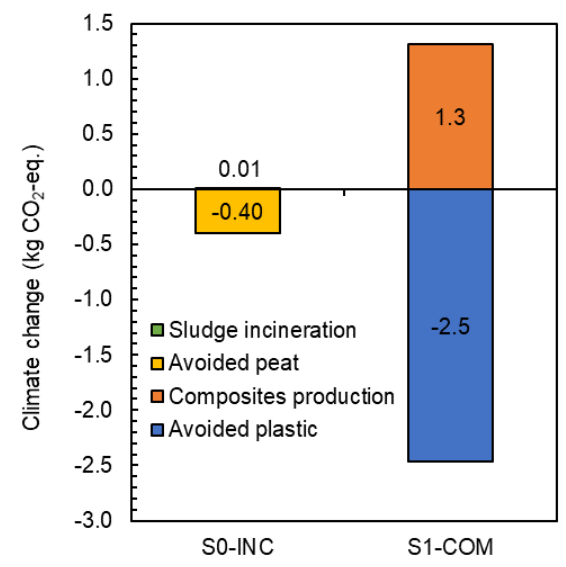

Figure 3. Impact on climate change from two studied scenarios.

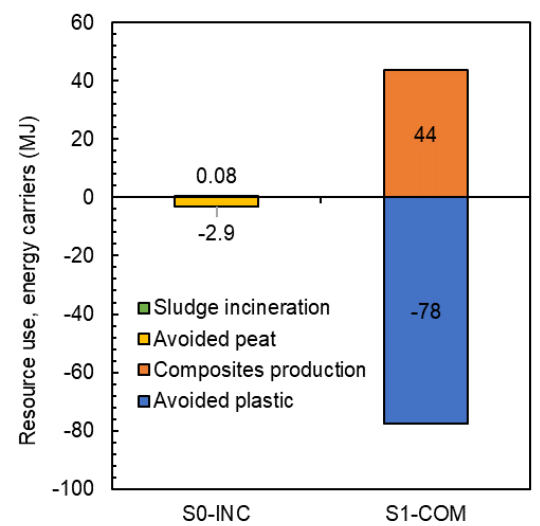

Figure 4. Consumption of fossil energy carries in the scenarios studied.

\subsection{Plastic Origin}

Virgin plastic was modelled in the production of composites in this study. However, recycled plastic can also be used (Liikanen et al., 2019). Unlike virgin plastic, plastic waste carries no burden with it if using the so-called "zero-burden" approach (Ekvall et al., 2007). The only impact associated with the plastic waste use is the impact from its crushing before the process. Figure 6 illustrates how the impact of using plastic waste significantly reduces the impact from the alternative scenario in comparison to the situation using virgin plastic. When plastic waste is used, the breakeven substitution ratio of 1:0.3 should be achieved for the alternative scenario to be more favorable than the current baseline.

\subsection{Impact of Properties}

The physical and other properties of composites can certainly differ from those of other materials which could potentially be replaced with the composites, such as herein studied plastic. However, accounting for the flexibility in the production of composites and their recipes, it could be expected that properties would be tailored based on specific application. Furthermore, the production process of composites could be adjusted so that smaller mass of material would be needed, if hollow products would be manufactured or products otherwise fitting into a specific application.

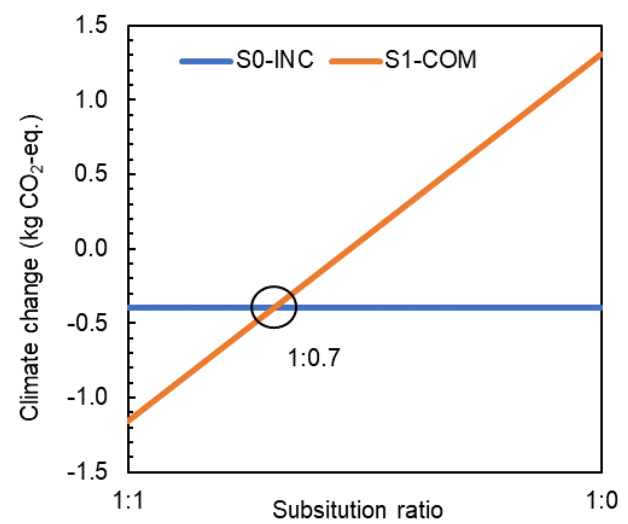

Figure 5. Impact of the plastic substitution ratio on the results.

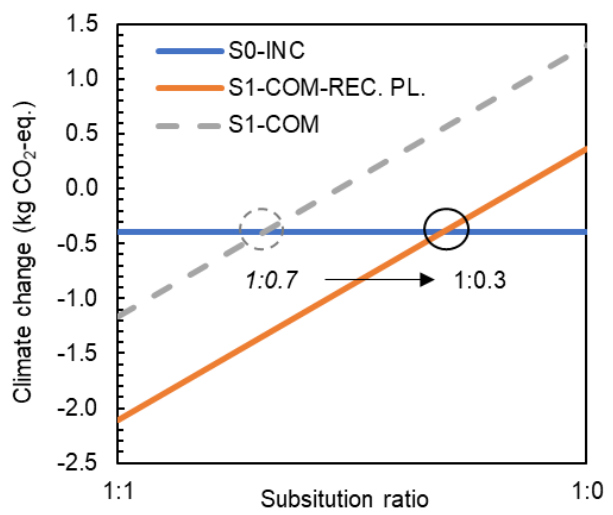

Figure 6. Impact of substitution of virgin plastic used in the composites production (S1-COM) with plastic waste (S1COM-REC. PL.).

\subsection{Impact of End-of-Life}

Additional data, such as that on the end-of-life of composites and substituted virgin plastic could further support the decision-making. Expectedly, the inclusion of incineration of composites and plastic products would further support the scenario of sludge use in composites since it would lead to a higher avoided impact from plastic incineration, while composites are $44 \%$ made of wood fibers.

\section{Conclusions}

LCA is a laborious and data-intensive method for the assessment of environmental impacts. Firstly, due to the need to gather a substantial amount of information on the inputs and 
outputs from the studied system. Secondly, due to the holistic approach considering the impacts across the entire life cycle, which however, could partly be limited.

On the other hand, LCAs can be built upon a substantial amount of data gathered in literature and databases to help decision-making at various levels, including those related to business operations. In this study, it was illustrated with the example of the utilization of primary sludge in composites. By looking into previously conducted research by the authors, the study identified that the use of primary sludge in composites production is a better option for mitigating climate change. Yet, the results are valid only if plastic is substituted at a high ratio.

Acknowledgments. The authors declare no conflict of interests. This research was funded by the Life IP on waste - Towards a circular economy in Finland (LIFE-IP CIRCWASTE-FINLAND) project (LIFE 15 IPE FI 004). Funding for the project was received from the EU Life Integrated program, companies and cities.

\section{References}

Bajpai, P. (2013). Biorefinery in the pulp and paper industry. Academic press. https://doi.org/10.1016/C2012-0-06724-5

Ilic, D.D., Eriksson, O., Ödlund, L., and Åberg, M. (2018). No zeroburden assumption in a circular economy. Journal of Cleaner Production, 182, 352-362. https://doi.org/10.1016/j.jclepro.2018.02. 031

Doustmohammadi, N. and Babazadeh, R. (2019). Design of closed loop supply chain of wood plastic composite (WPC) industry. Journal of Environmental Informatics, 35(2). https://doi.org/10.3808/jei. 201900419

Ekvall, T., Assefa, G., Björklund, A., Eriksson, O., and Finnveden, G. (2007). What life-cycle assessment does and does not do in assessments of waste management. Waste Management, 27(8), 989-996. https://doi.org/10.1016/J.WASMAN.2007.02.015

Faubert, P., Barnabé, S., Bouchard, S., Côté, R., and Villeneuve, C. (2016). Pulp and paper mill sludge management practices: What are the challenges to assess the impacts on greenhouse gas emissions? Resources, Conservation and Recycling, 108, 107-133. https://doi. org/10.1016/j.resconrec.2016.01.007

Fuchigami, Y., Kojiro, K., and Furuta, Y. (2020). Quantification of Greenhouse gas emissions from wood-plastic recycled composite (WPRC) and verification of the effect of reducing emissions through multiple recycling. Sustainability, 12(6), 2449. https://doi. org /10.3390/su12062449

Hilbert, M., and López, P. (2011). The world's technological capacity to store, communicate, and compute information. Science, 332 (6025), 60-65. https://doi.org/10.1126/science.1200970

Hong, J., Hong, J., Otaki, M., and Jolliet, O. (2009). Environmental and economic life cycle assessment for sewage sludge treatment processes in Japan. Waste Management, 29(2), 696-703. https://doi. org/10.1016/j.wasman.2008.03.026

Houillon, G., and Jolliet, O. (2005). Life cycle assessment of processes for the treatment of wastewater urban sludge: Energy and global warming analysis. Journal of Cleaner Production, 13, 287-299. https://doi.org/10.1016/j.jclepro.2004.02.022

Lahtela, V., Mustonen, K., and Kärki, T. (2017). The effect of primary sludge on the mechanical performance of high-density polyethylene composites. Industrial Crops and Products, 104, 129-132. https:// doi.org/10.1016/j.indcrop.2017.04.039

Liikanen, M., Grönman, K., Deviatkin, I., Havukainen, J., Hyvärinen, M., Kärki, T., Varis, J., Soukka, R., and Horttanainen, M. (2019). Construction and demolition waste as a raw material for wood poly- mer composites - Assessment of environmental impacts. Journal of Cleaner Production, 225, 716-727. https://doi.org/10.1016/j.jclepro. 2019.03.348

Liu, K.F.R., Liang, H.H., Chen, C.W., Chen, J.S., and Shen, Y.S. (2012). Combining scientific facts and significance criteria to predict the result of an environmental impact assessment review. Journal of Environmental Informatics, 19(2), 93-107. https://doi.org/10. 3808/jei.201200212

Lundin, M., Olofsson, M., Pettersson, G.J., Zetterlund, H. (2004). Environmental and economic assessment of sewage sludge handling options. Resources, Conservation and Recycling, 41(4), 255-278. https://doi.org/10.1016/j.resconrec.2003.10.006

Mustonen, K., Lahtela, V., and Kärki, T. (2019). The impact of primary sludge on the physical features of high-density polyethylene (HDPE) composites. Resources, 8(4), 184. https://doi.org/10.3390/ resources 8040184

Ojanen, P. (2001). Selluja paperitehtaiden lietteiden käsittely ja hyötykäyttö sekä niitä rajoittavat tekijät.

Finnish Standards Association SFS-EN ISO 14040. (2006). Environmental management: Life cycle assessment. Principles and framework.

Finnish Standards Association SFS-EN ISO 14044. (2006). Environmental management: Life cycle assessment. Requirements and guidelines.

Sommerhuber, P.F., Wenker, J.L., Rüter, S., and Krause, A. (2017). Life cycle assessment of wood-plastic composites: Analysing alternative materials and identifying an environmental sound end-of-life option. Resources, Conservation and Recycling, 117, 235-248. https: //doi.org/10.1016/J.RESCONREC.2016.10.012

Sphera. (2020). Environmental Footprint (EF)/ILCD recommendation. http://www.gabi-software.com/finland/support/gabi/gabi-lcia-docu mentation/environmental-footprint-efilcd-recommendation/.

Sphera. (2017a). Process data set: Wood (natural) in municipal waste incineration plant; waste-to-energy plant with dry flue gas treatment, without collection, transport and pre-treatment; production mix (region specific plants), at plant; $18.0 \mathrm{MJ} / \mathrm{kg}$ net calorific value. http: //gabi-documentation-2018.gabi-software.com/xml-data/processes/ 9a8854e3-a953-44a7-9d7a-134c701ea57e.xml.

Sphera. (2017b). Process data set: Plastic extrusion profile (unspecific); technology mix; single route, at plant. http://gabi-documentation2018.gabi-software.com/xml-data/processes/d26e6276-9582-49f0bd90-82189d485e1d.xml.

Sphera. (2014a). Process data set: Electricity from peat; AC, mix of direct and CHP, technology mix regarding firing and flue gas cleaning; production mix, at power plant; $1 \mathrm{kV}-60 \mathrm{kV}$. http://gabidocumentation-2018.gabi-software.com/xml-data/processes/bfb6a 71c-c06b-444f-82d9-20c4d0714477.xml.

Sphera. (2014b). Process data set: Lubricants at refinery; from crude oil; production mix, at refinery; $38 \mathrm{MJ} / \mathrm{kg}$ net calorific value. http:// gabi-documentation-2018.gabi-software.com/xml-data/processes/ bdfac21c-7415-46af-acbc-8916cb95b9b8.xml.

Sphera. (2014c). Process data set: Electricity grid mix 1 kV-60 kV; AC, technology mix; consumption mix, to consumer; $1 \mathrm{kV}-60 \mathrm{kV}$. http:// gabi-documentation-2018.gabi-software.com/xml-data/processes/6 dd69400-9e1d-4376-a6f3-260877acd19 4.xml.

Sphera. (1999). Process data set: Polyethylene high density granulate (PE-HD); technology mix; production mix, at plant. http://gabidocumentation-2018.gabi-software.com/xml-data/processes/0704c 700-2fb0-43c5-8803-bed8a6f1b968.xml.

Suh, Y.J., and Rousseaux, P. (2002). An LCA of alternative waste- water sludge treatment scenarios. Resources, Conservation and Recycling, 35(3), 191-200. https://doi.org/10.1016/S0921-3449(01)001 20-3

Väntsi, O., and Kärki, T. (2015). Environmental assessment of recycled mineral wool and polypropylene utilized in wood polymer composites. Resources, Conservation and Recycling, 104, 38-48. https://doi.org/10.1016/j.resconrec.2015.09.009 